Araştırma Makalesi/Research Article

\title{
Bazı Yerli Tip Üzüm (Vitis Vinifera L.) Çeşitlerinin Budama Sürgünlerinin Kesme Özelliklerinin Belirlenmesi
}

\author{
F. Göksel Pekitkan ${ }^{1} \quad$ A. Konuralp Eliçin ${ }^{2} \quad$ Abdullah Sessiz $^{3^{*}}$ \\ 1,2,3 Dicle Üniversitesi, Ziraat Fakültesi Tarım Makinaları ve Teknolojileri Mühendisliği Bölümü, Diyarbakır \\ *Sorumlu yazar e-posta: asessiz@ dicle.edu.tr \\ ${ }^{1}$ https://orcid.org/0000-0002-7791-7963, ${ }^{2}$ https://orcid.org/0000-0003-3240-4547, ${ }^{3}$ https://orcid.org/0000-0002-3883-0793
}

Geliş Tarihi: 18.07.2019

Kabul Tarihi: 18.12.2019

\section{$\ddot{O} z$}

Bağcılıkta budama ve hasat işlemleri işgücü temini, zamanın etkin kullanımı, ürün kayıpları, kalite ve üretim maliyetleri açısından en kritik olanlardır. Bağ budama işlerinde kullanılacak mekanik araçlar veya budama makaslarının tasarımı ve enerjinin etkin kullanımı için budaması yapılacak asma çeşidinin sürgün kesme kuvveti, kesme gerilmesi ve kesme enerjisi gibi özelliklerinin bilinmesi önemlidir. Bu çalışmada, băg çubuklarının kesme işlerinde kullanılabilecek bir makinanın tasarımında veya bir budama makasının, kesmede temel parametreler olan kesme kuvveti, kesme gerilmesi ve enerji gereksiniminin belirlenmesi amaçlanmıştır. Bu amaç doğrultusunda başta Diyarbakır ili ve çevresi olmak üzere Güneydoğu Anadolu Bölgesinde yetiştirilen Şire, Öküzgözü ve Boğazkere üzüm çeşitlerinin bıçak tipi, kesme açısı ve kesme hızına bağlı olarak asmaların sürgün kesme özellikleri incelenmiştir. Deneylerde kullanılan asmaların sürgünleri Diyarbakır ilindeki şaraplık üzüm üreten üreticilere ait bağlardan temin edilmiştir. Sürgünlerin kesme özelliklerinin belirlenmesinde Llyod LRX plus, $2500 \mathrm{~N}$ kapasiteli biyolojik malzeme test cihazı kullanılmıştır. Elde edilen sonuçlara göre, her üç çeşit için kesme özellikleri, bıçak tipi, kesme açısı ve yükleme durumuna göre değişikliklikler göstermiştir. Kesme kuvveti ve enerji gereksinimi her çeşit ve bıçak tipi için ayrı olmuştur. Genel olarak tırtıklı ağza sahip bıçaklarda kesme kuvveti ve enerji değeri düz-ince ağza sahip olan bıçak tipinde daha yüksek olmuştur. Bıçak kesme açısı arttıkça kesme kuvveti ve kesme enerjisi azalmıştır. En yüksek kesme kuvveti ve enerji değerleri $0^{\circ}$ düşey yönde yapılan kesmede gerçekleşmiştir. Kesme hızlarının artışı kesme kuvveti, kesme gerilmesi, kesme enerjisi ve spesifik kesme enejisini hafif bir şekilde arttırmıştır. Tüm çeşitlerde en düşük değerler $2 \mathrm{~mm} \mathrm{~s}^{-1}$ 'lik yükleme hızlarında elde edilmiştir.

Anahtar Kelimeler: Bağ, bıçak tipi, kesme kuvveti, kesme enerjisi

\section{Determination of Shearing Properties in Grape Pruning Cane in Some Domestic Grape Varieties}

\section{Abstract}

Pruning and harvesting process in viticulture are the most critical in terms of labor supply, effective use of time, product losses, quality and production costs. It is important to know the properties such as the shear force, shear stress and shear energy of the grape variety to be pruned for the design and effective use of the mechanical tools or pruning shears to be used in vineyard pruning. In this study, it is aimed to determine the basic parameters such as shear force, shear stress and energy requirement in the design of a machine that can be used in cutting work of gape canes. For this purpose, the variation of cutting properties depending on knife type, knife-edge angle and Cutting speed for Şire, Öküzgözü and Boğazkere grape varieties were investigated. The canes of grape used in the experiments were obtained from the vineyards of wine producing grape producers in Diyarbakır Province. Llyod LRX plus, a $2500 \mathrm{~N}$ capacity biological material tester, was used to determine the shear properties of gape canes. According to the results, the cutting properties were changed dependin gon the knife type, cutting angle and loading speed for all grape varieties. The shear force and energy requirements were different for varieties and types of knives. In general, the cutting force and energy value is higher in sarrated type knives than flat-thin knife. As the blade cutting angle increased, the cutting force and cutting energy decreased. The highest shear force and energy values were obtained in the $0^{\circ}$ vertical direction. The increase of cutting speeds has slightly increased the cutting force, cutting resistance, cutting energy and the specific cutting energy. The lowest values were obsorved at loading speeds of $2 \mathrm{~mm} \mathrm{~s}^{-1}$ for all grape varieties.

Keywords: Vineyard, knife type, cutting force, cutting energy 


\section{Giriş}

Üzüm; sofralık, kuru üzüm, üzüm suyu ve şarap olarak tüketildiğinden neolotik çağlardan günümüze kadar insanlar için çok önemli ve değerli bir tarımsal ürün olmuştur. 2017 yılında Dünyada sofralık üzüm üretimi 22.7 milyon tona ulaşmıştır (Anastasiou ve ark., 2018). Dünyada olduğu gibi Türkiye'de de gerek beslenmede gerek ticari olarak daima önemli ve değerli bir ürün olmuştur. Dünya pazarlarında rekabet etmek ve karlı bir üretimin gerçekleşebilmesi için olanaklar dahilinde üretim girdilerinin en aza indirilmesi sağlanmalıdır. Karlı bir üretimin temel yolu, insan işgücünü en aza indiren mekanik araç ve gereçlerin kullanılmasıdır. Oysa ülkemizin genelinde olduğu gibi bölgemiz ve özelde Diyarbakır ilinde maliyeti yüksek olan budama ve hasat işlerinin tümü insan tarafından makas kullanılarak el emeğine dayalı olarak yapılmaktadır. $\mathrm{Bu}$ işlem yorucu, zaman alıcı ve enerji gereksinimi fazla olan bir süreçtir. Genellikle budamada ve üzüm hasadında ağzı düz olan budama makasları kullanılmaktadır. Bu da üretim sürecini uzatmanın yanı sıra üzüm kayıplarının artmasına ve kalitenin düşmesine neden olmaktadır. Ayrıca, deneyimli işgücü temininde yaşanan sorunlar, işgücü maliyetlerinin artması, işlerin zamanında yapılamaması gibi nedenlerden dolayı bağ sahiplerini mekanizasyon araçlarının ve mekanik ekipmanların kullanımına zorlamıştır.

Güneydoğu Anadolu Bölgesinde yaygın olarak yetiştirilen üzüm çeşitleri Şire, Boğazkere ve Öküzgözü çeşitleridir. Farklı dönemlerde bu üzüm bağlarında sürgün budaması yapılmaktadır. Bağcılıkta budama ve hasat işlemleri işgücü temini, zamanın etkin kullanımı, ürün kayıpları, kalite ve üretim maliyetleri açısından en kritik olanlardır. Bu yüzden budama ve hasat işlemlerinde mekanizasyon araçlarının ve mekanik ekipmanlarının kullanımı oldukça önemlidir (Morris, 2000; Sessiz ve ark. 2015). Bağ budama işlerinde kullanılacak mekanik araçlar veya budama makaslarının tasarımı ve enerjinin etkin kullanımı için budaması yapılacak asma çeşidinin sürgün kesme kuvveti, kesme gerilmesi ve kesme enerjisi gibi özelliklerinin bilinmesi önemlidir. Kesme kuvveti ve enerji gereksinimi; kesilecek bitkinin çeşidine, çapına, olgunlaşma durumuna, nem içeriğine ve gövde yapısının yanı sıra kullanılacak bıçak tipi, ağız yapısı, kesme açısı ve kesme hızı gibi özelliklere bağlıdır (Persson, 1987; Ammer Eissa ve ark. 2008; Ghahraei ve ark., 2011; Taghijarah ve ark. 2011; Nowakowski, 2016). Bıçak, kesme açısı ve bıçak tipi, kesme kuvveti ve enerjisine doğrudan etkili faktörlerdir.

Güneydoğu Anadolu Bölgesinde yaygın olarak Şire, Öküzgözü ve Boğazkere üzüm çeşitleri yetiştirilmektedir. Budama ve salkım hasadında düz ağza sahip budama makasları kullanılmaktadır. $\mathrm{Bu}$ çalışmanın temel amacı, bağlarda sürgün budama işlerinde kullanılan düz ağız yapısına sahip makaslara alternatif olabilecek tırtıklı bıçak tiplerini kesme özellikleri bakımından karşılaştırmaktır. Çalışmada farklı özelliklere sahip olan Şire, Öküzgözü ve Boğazkere üzüm çeşitleri için üç farklı bıçak tipini kullanarak farklı bıçak kesme açılarında ve kesme hızlarında sürgünlerin kesme kuvveti, kesme gerilmesi, kesme enerjisi ve özgül kesme enerjisi gibi kesme özelliklerinin belirlenmesi ve karşılaştırılması amaçlanmıştır. Bu amaç doğrultusunda her üzüm çeşidi için en uygun bıçak tipi, bıçak kesme açısı ve kesme hızı belirlenecektir.

\section{Materyal ve Yöntem}

Denemede kullanılan Şire, Öküzgözü ve Boğazkere (Vitis vinifera L.) asma sürgünleri (Şekil 1) 2018 yılında Diyarbakır GAP Uluslararası Tarımsal Araştırma ve Uygulama Merkezindeki bağ alanlarından temin edilmiştir. Bağlardan alınan sürgünlerin nem kaybını önlemek için üzerindeki yapraklar uzaklaştırılmış ve denemeler süresince bağ çubuklarının nem kaybını önlemek için Tarım Makinaları ve Teknolojileri Mühendisliği Bölümünde $5^{\circ} \mathrm{C}$ 'ye ayarlı bir buzdolabında muhafaza edilmiştir.

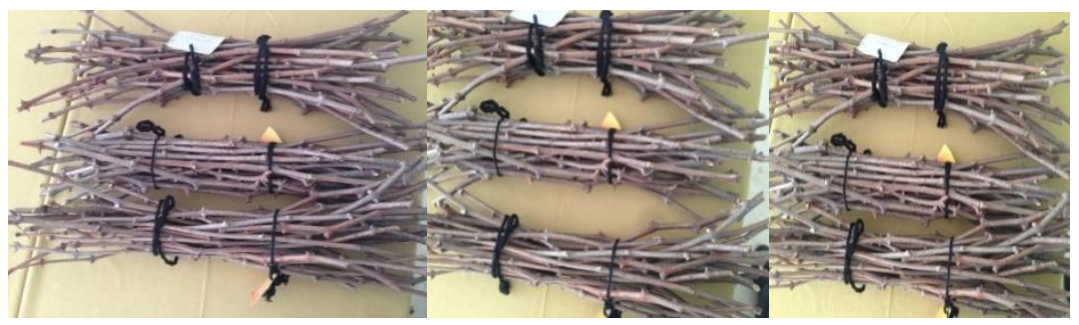

Şekil 1. Denemelerde kullanılan bağ çubuklarına ait örnekler. 
Kesme testlerinde her üç çeşit için 10 mm'lik çapa sahip sürgünler kullanılmıştır. Dal çapları ve nem içeriklerinin mümkün olduğunca aynı olmasına dikkat edilmiştir. Her çap için denemeler üç tekrarlı olarak yürütülmüştür. Çap değerlerinin ölçülmesinde dijital kumpas kullanılmıştır. 10 mm'lik çaplar kesit alanına $\left(50.24 \mathrm{~mm}^{2}\right)$ dönüştürülerek bu değer için kesme kuvveti ve kesme enerjisi belirlenmiştir. Deneylere başlamadan önce sürgünlerin nem içeikleri ASABE (2006) standartlarına göre $105^{\circ} \mathrm{C}^{\prime} \mathrm{de} 24$ saat firında kurutma yöntemine göre belirlenmiştir. Testler sırasındaki sürgün nem içerikleri, Şire çeşidi için ortalama \% 36.30 ( $\sigma: 0.5)$, Boğazkere çeşidi için \% 35.10 ( $\sigma: 0.5)$ ve Öküzgözü çeşidi için \% 36.80 ( $\sigma: 1.1)$ olarak ölçülmüştür.

Kesme deneyleri Llyod LRX marka 2500 N, \%0.5 hassasiyetli kuvvet ölçme sensörüne sahip olan biyolojik malzeme test cihazı ve NEXYGEN Data Analysis yazılımı (Şekil 2) kullanılmıştır. Denemelerde her çeşit için kesme ağzı tırtıkl1-kalın, kesme ağzı tırtıkl1-ince ve kesme ağzı düz-ince olan üç farklı bıçak tipi kullanılmıştır. Denemeler $0^{\circ}, 10^{\circ}, 20^{\circ}, 30^{\circ}$ ve $40^{\circ}$ beş farklı biçak kesme açılarında ve 2, 3, 4, 5 ve $6 \mathrm{~mm} \mathrm{~s}^{-1}$ beş farklı yükleme hızlarında yapılmıştır (Şekil 2). Denemelerde sürgünler kesme platformunun altına yerleştirilerek iki ucundan sabit tutarak yükleme yapılmıştır.
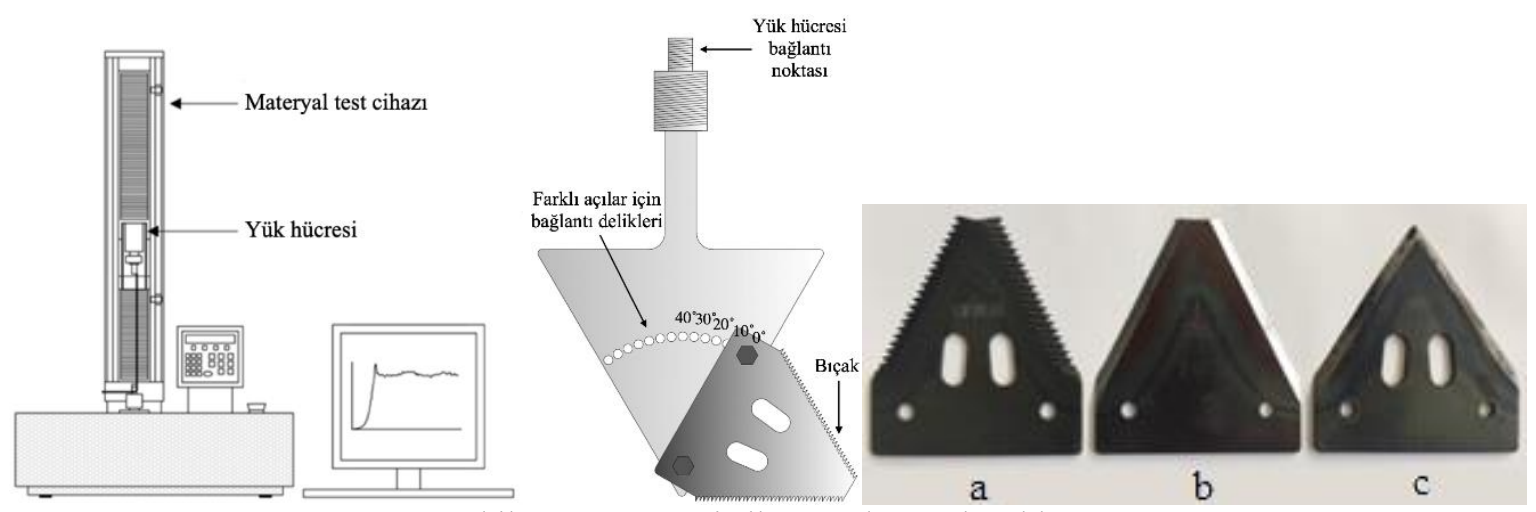

Şekil 2. Kesme testi cihazı ve kesme bıçakları

(a-kesme ağzı turtıklı-kalın, b-kesme ağzı tırtıklı-ince, c-kesme ağzı düz-ince bıçak)

Cihaz tarafindan ölçülen en büyük kesme kuvveti değerlerinden aşağıda verilen eşitlik kullanılarak kesilme gerilmesi hesaplanmıştır (Mohsenin, 1986; Güzel ve Zeren, 1989; Beyhan, 1996; Kocabıyık ve Kayışoğlu, 2004; Sessiz ve ark. 2013; Esgici ve ark., 2017).

$$
\mathrm{G}_{\max }=\frac{\mathrm{F}_{\max }}{\mathrm{A}}
$$

Burada;

$\mathrm{G}_{\max }$ : Maksimum kesme gerilmesi (MPa),

$\mathrm{F}_{\max }$ : Maksimum kesme kuvveti $(\mathrm{N})$

A: Sürgün kesit alanını $\left(\mathrm{mm}^{2}\right)$ ifade etmektedir

Kesme enerjisi; maksimum kesme kuvveti, sürgün çapı ve nem içeriği ile ilişkilidir. $\mathrm{Bu}$ yüzden kesme enerjisi; kesme kuvveti ve alınan yola bağlı olarak test cihazı tarafından kaydedilen kuvvet-deformasyon eğrisi altında kalan alanın NEXYGEN Data Analysis yazılımı tarafından hesaplanarak elde edilmiştir (Yore ve ark., 2002; Chen ve ark. 2004; Kocabıyık ve Kayışoğlu, 2004; Nazari ve ark. 2008; Ekinci ve ark. 2010; Zareiforoush ve ark. 2010; Heidari ve Chegini, 2011; Ozdemir ve ark., 2015; Nowakowski, 2016; Pekitkan ve ark., 2018; Sessiz ve ark. 2018).

Özgül enerji tüketim (ÖET) aşağıda verilen eşitlik kullanılarak hesaplanmıştır (Mohsenin, 1986; Lu ve Siebenmorgen, 1995; Emadi ve ark., 2004; Pekitkan ve ark., 2018; Sessiz ve ark. 2018).

$$
\mathrm{E}_{\overline{\text { öet }}}=\frac{\mathrm{Et}}{\mathrm{A}}
$$

Burada; 


\section{$\mathrm{E}_{\text {öet }}$ Özgül enerji tüketimi $\left(\mathrm{J} \mathrm{mm}^{-2}\right)$}

$\mathrm{E}_{\mathrm{t}}$ : maksimum kesme enerjisini $(\mathrm{J})$ ifade etmektedir.

Veriler arasındaki istatistiksel karşılaştırma için JMP 11. Version paket programı kullanılmıştır. Denemeler varyans analiz yöntemi (ANOVA) kullanılarak tesadüfü parsel deneme desenine göre planlanmıştır. Karşılaştırmalar TUKEY testi ile \% 5 önem derecesine göre yapılmıştır.

\section{Sonuçlar ve Tartışma}

Araştırmada kullanılan Şire, Boğazkere ve Öküzgözü çeşitlerin sürgün çubuklarına ait elde edilen kesme kuvvetleri Şekil 3'de, kesme gerilmesi Şekil 4'de, kesme enerjisi Şekil 5'te ve özgül kesme enerjisi değerleri Şekil 6'da toplu olarak verilmiştir

\section{Bıçak tipi, kesme açısı ve kesme hızının kesme kuvvetine etkisi}

Her üç çeşit için kesme kuvvetine ilişkin ortalama veriler Şekil 3'de toplu olarak verilmiştir. Yapılan varyans analiz sonuçlarına göre bıçak tipi, kesme açısı ve kesme hızının sürgün kesme kuvveti üzerine etkisi tüm çeşitler için önemli bulunmuştur $(\mathrm{p}<0.05)$.

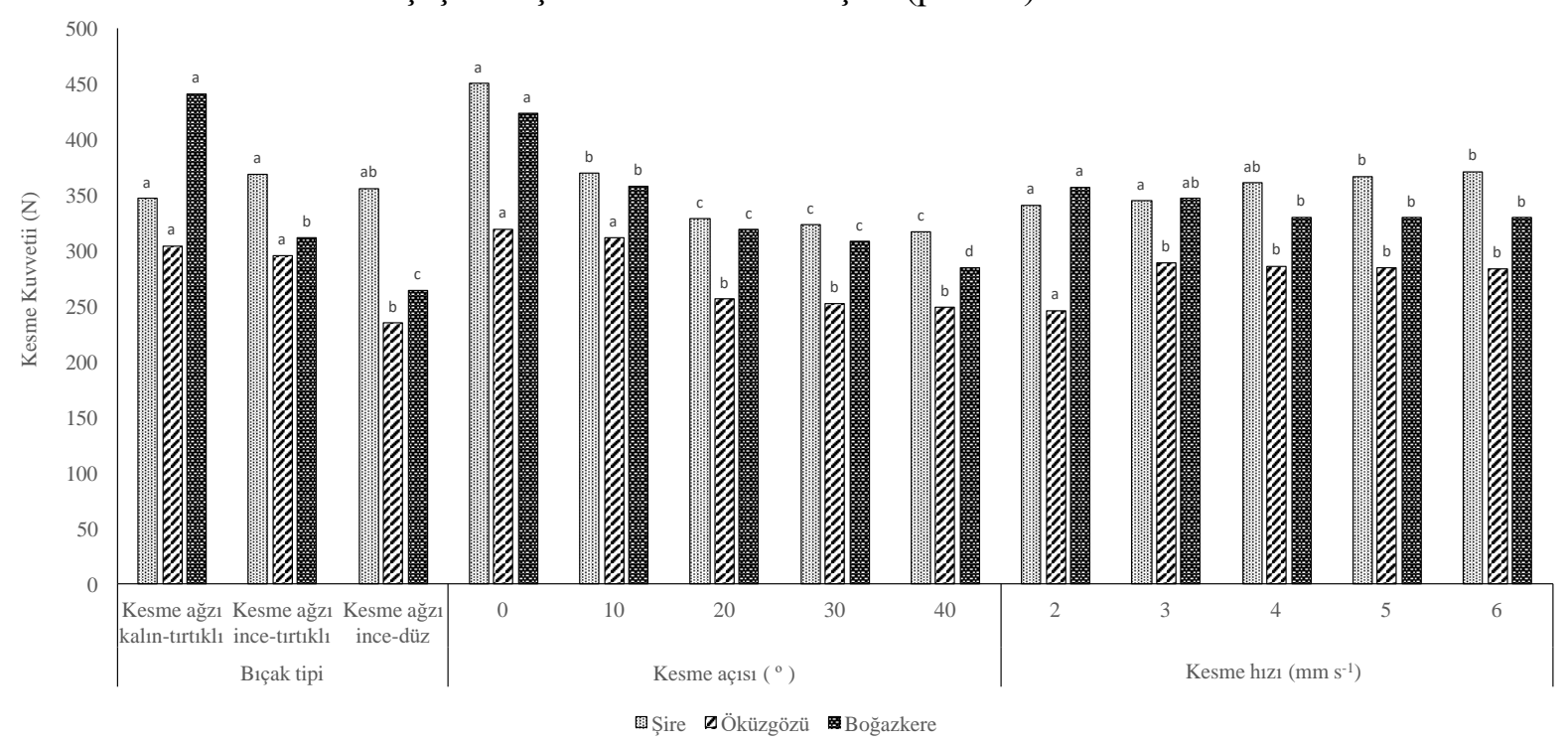

*Aynı harfle gösterilen ortalama değerler arasında \% 5 önem derecesine göre fark yoktur.

Şekil 3. Kesme kuvvetinin bıçak tipi, kesme açısı ve kesme hızına bağlı olarak değiş̧imi.

Şekil 3'den görüleceği gibi Şire ve Öküzgözü çeşitlerinde kesme ağzı tırtıklı olan her iki bıçak tipleri arasında kesme kuvveti bakımından önemli bir fark bulunmaz iken, tırtıklı ağza sahip bıçak tipleri ile ince-düz ağza sahip bıçak tipi arasındaki fark istatistiksel olarak önemli bulunmuştur. Buna karşın Boğazkere çeşidi için her üç bıçak tipi arasındaki fark önemli bulunmuştur $(p<0.05)$.

En düşük kesme kuvveti değerleri kesme ağzı ince-düz olan bıçak çeşidinde elde edilmiştir. Bu bıçak tipinde elde edilen en düşük kesme kuvveti değeri $234.50 \mathrm{~N}$ ile Öküzgözü çeşidinde elde edilirken, en yüksek değer Şire çeşidinde $355.8 \mathrm{~N}$ olarak elde edilmiştir. En büyük kesme kuvveti değerleri ise kesme ağzı kalın-tırtıklı bıçak tipinde, büyükten küçüğe sırasıyla Boğazkere, Şire ve Öküzgözü çeşidinde elde edilmiştir. Bu durum farklı tip kesme bıçakları kullanılsa dahi her çeşit için sürgünlerin kesme gereksinimlerinin farklı olduğunu göstermektedir. Bıçak kesme açılarının kesme kuvveti üzerine olan etksi de tüm çeşitlerde önemli bulunmuştur $(\mathrm{p}<0.05)$. Biçak kesme açısı yatay yönde arttıkça kesme kuvveti gereksinimi azalmıştır. En yüksek kesme kuvveti yatay ile $0^{\circ}$ açıda yapılan kesme testlerinde elde edilmiştir. Kesme açısına bağlı olarak en yüksek değerler Şire çeşidinde elde edilirken, sırasıyla onu Boğazkere ve Öküzgözü çeşidi takip etmiştir. Genel olarak $20^{\circ}, 30^{\circ}$ ve $40^{\circ}$ bıçak kesme açılarında tüm çeşitlerde kesme kuvvetleri arasındaki fark önemsiz bulunmuştur. Şekil 3'den görüleceği gibi kesme hızının (yükleme hızı) kesme kuvveti üzerine etkisi de önemli olmuş, Şire ve Öküzgözü çeşitlerinde pozitif yönde, Boğazkere çeşidinde ise negatif yönde bir ilişki gerçekleşmiştir. Ancak, artış $3 \mathrm{~mm} \mathrm{~s}^{-1}$ lik yükleme hızından sonraki hızlar için gerek rakamsal ve 
gerek istatistiki olarak değişmemiştir. Diğer bir deyişle tüm çeşitler için $4 \mathrm{~mm} \mathrm{~s}^{-1}, 5 \mathrm{~mm} \mathrm{~s}^{-1}$ ve $6 \mathrm{~mm} \mathrm{~s}^{-}$ ${ }^{1}$ 'lik yükleme hızlarında elde edilen değerler arasındaki fark önemsiz olmuştur. Yükleme hızlarına bağlı olarak en yüksek kesme kuvveti değeri sırasıyla Şire, Boğazkere ve Öküzgözü çeşidinde elde edilmiştir.

\section{Bıçak tipi, kesme açısı ve kesme hızının kesme gerilmesine etkisi}

Her üç çeşit için kesme gerilmelerine ilişkin ortalama veriler Şekil 4'de toplu olarak verilmiştir. Varyans analiz sonuçlarına (ANOVA) göre bıçak tipi, kesme açısı ve kesme hızının kesme gerilmesine olan etkisi her üç çeşit için önemli bulunmuştur $(p<0.05)$.

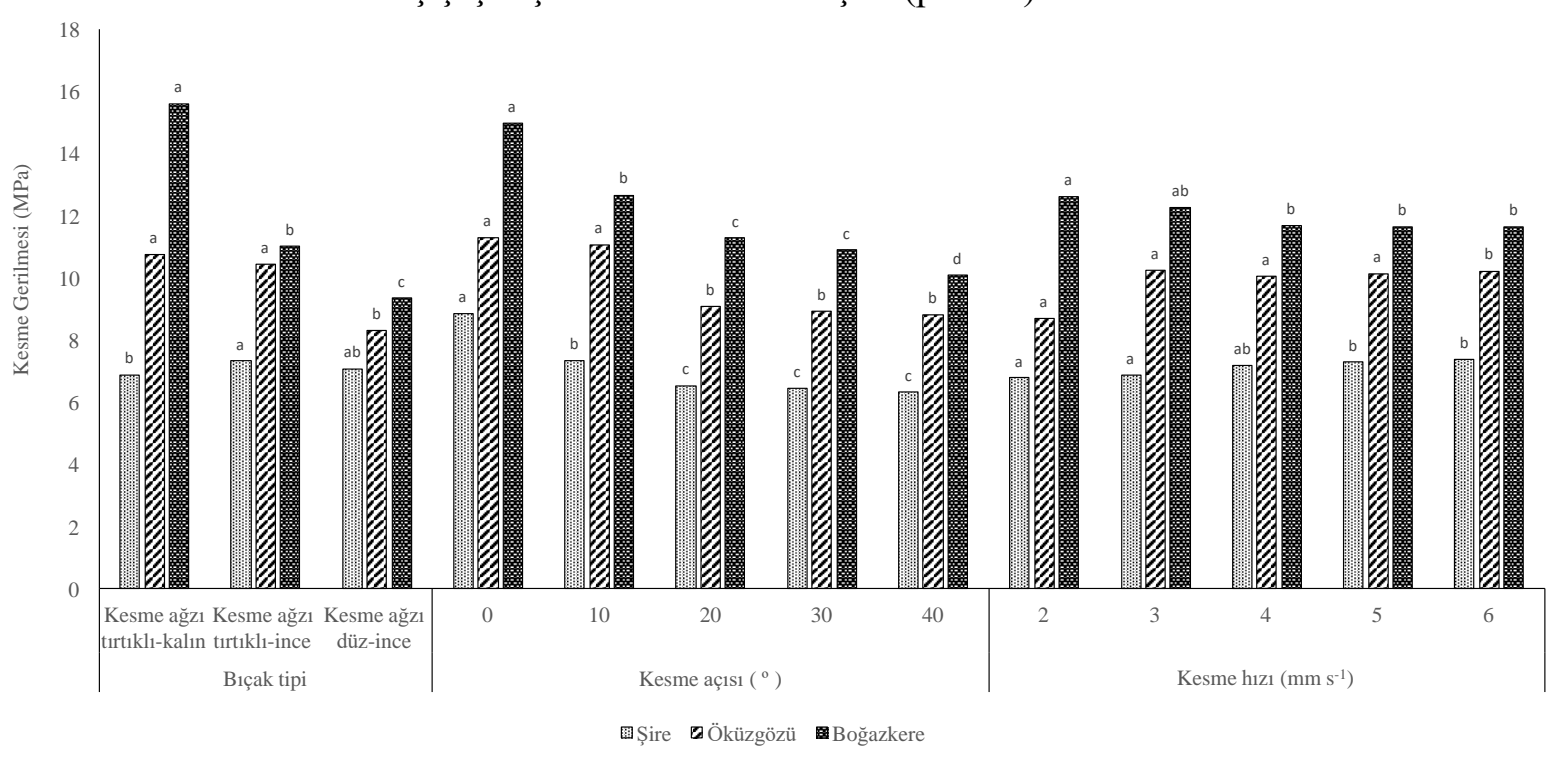

*Aynı harfle gösterilen ortalama değerler arasında \% 5 önem derecesine göre fark yoktur.

Şekil 4. Bıçak tipi, kesme açısı ve kesme hızına bağlı olarak kesme gerilmesinin değişimi.

Şekil 4'den görüleceği gibi tüm çeşitlerde bıçak tipleri arasındaki fark önemli bulunurken, en yüksek kesme gerilmesi kesme ağzı tırtıklı-kalın tip bıçakta elde edilmiştir. Onu sırasıyla kesme ağzı tırtıklı-ince bıçak ve kesme ağzı düz-ince bıçak tipleri izlemiştir. Tüm bıçak tipleri için en yüksek kesme gerilmesi Boğazkere çeşidinde elde edilmiştir. Yüksek kesme kuvvetlerine karşın en düşük kesme gerilmesi değerleri Şire çeşidinde elde edilmiştir. Bıçak kesme açılarının kesme gerilmesine etkisi de tüm çeşitlerde istatistiksel olarak önemli bulunmuştur $(\mathrm{p}<0.05)$. Kesme açısı arttıkça kesme gerilmesi değerleri bütün çeşitlerde azalmıştır. En yüksek kesme kuvveti düşey yönde $0^{\circ}$ açıyla yapılan kesme işleminde ve Boğazkere çeşidinde $14.97 \mathrm{MPa}$ olarak elde edilmiştir. Bıçak tipinde olduğu gibi kesme açısına bağlı olarak en düşük kesme gerilmesi değerleri Şire çeşidinde elde edilmiştir. Genel olarak $20^{\circ}$ kesme açısından sonra yapılan kesme işlemlerinde kesme gerilmeleri arasında tüm çeşitler için önemli bir fark bulunmamıştır. Şekil 4'de kesme hızının kesme gerilmesi üzerine etkisi incelendiğinde, kesme hızı artıkça kesme gerilmesi değerleri tüm çeşitlerde az bir miktar artış göstermiştir. $3 \mathrm{~mm} \mathrm{~s}^{-1}$ lik yükleme hızından sonraki hızlarda bütün çeşit ve bıçak tiplerinde istatistiksel olarak bir değişim olmamış, söz konusu hızlar arasındaki fark istatistiki olarak önemsiz bulunmuştur.

\section{Bıçak tipi, kesme açısı ve kesme hızının kesme enerjisine etkisi}

Her üç çeşit için kesme kuvveti-uzama değerlerinden elde edilen maksimum kesme enerjisine ilişkin ortalama veriler Şekil 5'te toplu olarak verilmiştir. Varyans analiz sonuçlarına (ANOVA) göre bıçak tipi, kesme açısı ve kesme hızının kesme enerjisine etkisi her üç çeşit için önemli bulunmuştur $(\mathrm{p}<0.05)$. 


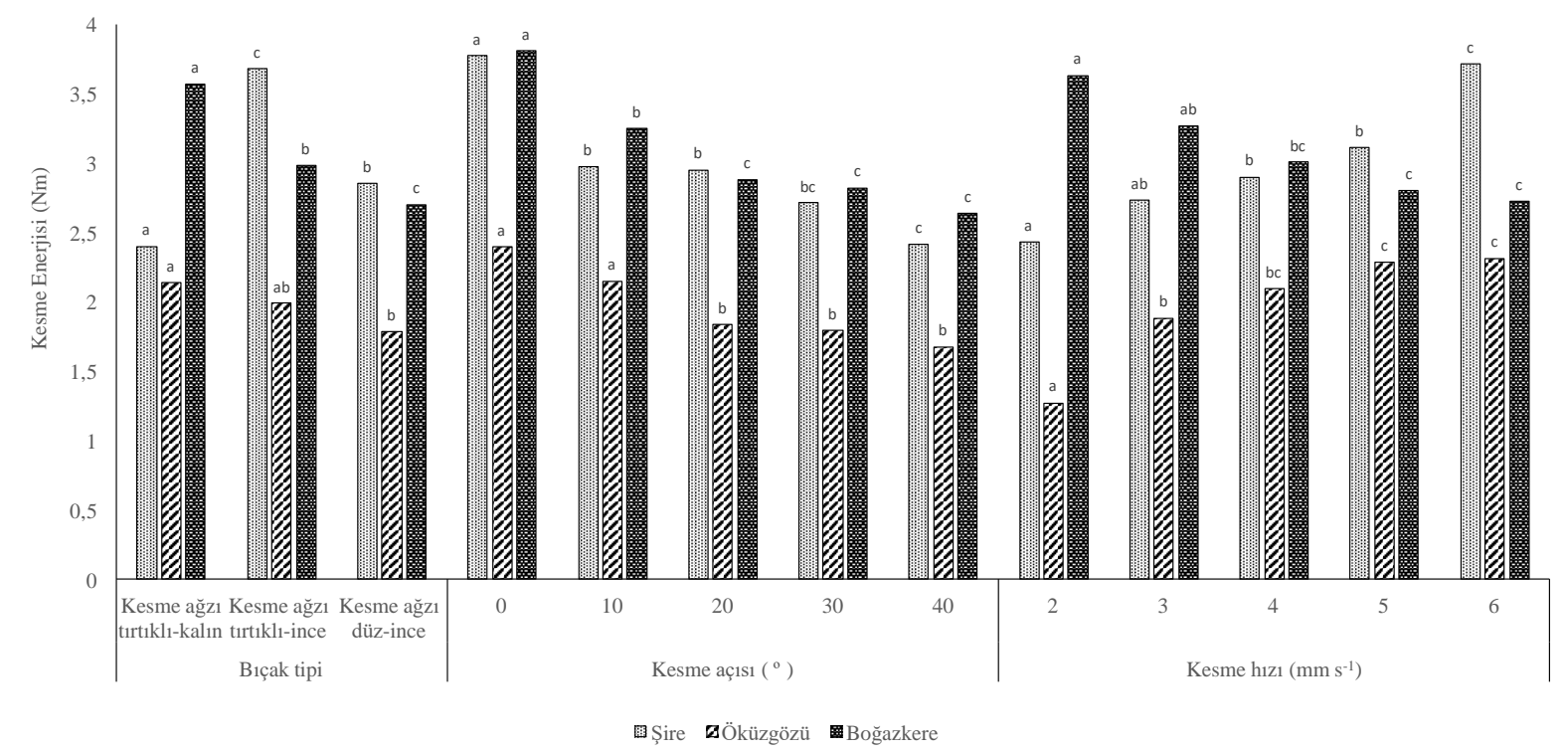

*Aynı harfle gösterilen ortalama değerler arasında \% 5 önem derecesine göre fark yoktur.

Şekil 5. Bıçak tipi, kesme açısı ve kesme hızına bağlı olarak kesme enerjisi

Şekil 5’ten görüleceği gibi tüm çeşitler için bıçak tipleri arasındaki fark önemli bulunmuş, enerji gereksinimi çeşit ve bıçak tipine göre farklılıklar göstermiştir. Kesme açısı yatay yönde arttıkça kesme enerjisi değerleri azalmıştır. En yüksek kesme enerjisi $0^{\circ}$ açıyla yapılan kesmede gerçekleşmiştir. Kesme enerjisi bakımından tüm çeşit ve bıçak tiplerinde benzer sonuçlar elde edilmiştir. Üç çeşit için de $20^{\circ}, 30^{\circ}$ ve $40^{\circ}$ kesme açılarında elde edilen kesme enerjisi değerleri arasındaki farklar önemsiz bulunmuştur. Kesme hızı dikkate alındığında en yüksek kesme enerjisi değerleri, en düşük kesme hızı olan $2 \mathrm{~mm} \mathrm{~s}^{-1}$ 'lik hızda elde edilmiştir. Bu hız değerinden sonra kesme hızları arttıkça Şire ve Öküzgözü çeşitlerinde artış olurken, Boğazkere çeşidinde azalma olmuştur. Bu çelişkili durum muhtemelen çeşit özelliğinden kaynaklanmaktadır. Ancak bu değişim $4 \mathrm{~mm} \mathrm{~s}^{-1}$ lik yükleme hızından itibaren tüm çeşitlerde istatistiki olarak önemsiz olmuştur. Genel olarak tüm çeşitler için $4 \mathrm{~mm} \mathrm{~s}^{-1}, 5 \mathrm{~mm} \mathrm{~s}^{-1}$ ve $6 \mathrm{~mm} \mathrm{~s}^{-1}$ lik yükleme hızlarının kesme enerjisine olan etkisi önemsiz olmuştur.

\section{Bıçak tipi, kesme açısı ve kesme hızının kesme özgül enerji gereksinimine etkisi}

Her üç çeşit bıçak tipi, kesme açısı ve kesme hızına bağlı olarak elde edilen özgül kesme enerjisine ilişkin ortalama veriler Şekil 6'da verilmiştir. Varyans analiz sonuçlarına (ANOVA) göre bıçak tipi, kesme açısı ve kesme hızının kesme enerjisine etkisi her üç çeşit için önemli bulunmuştur $(\mathrm{p}<0.05)$. 


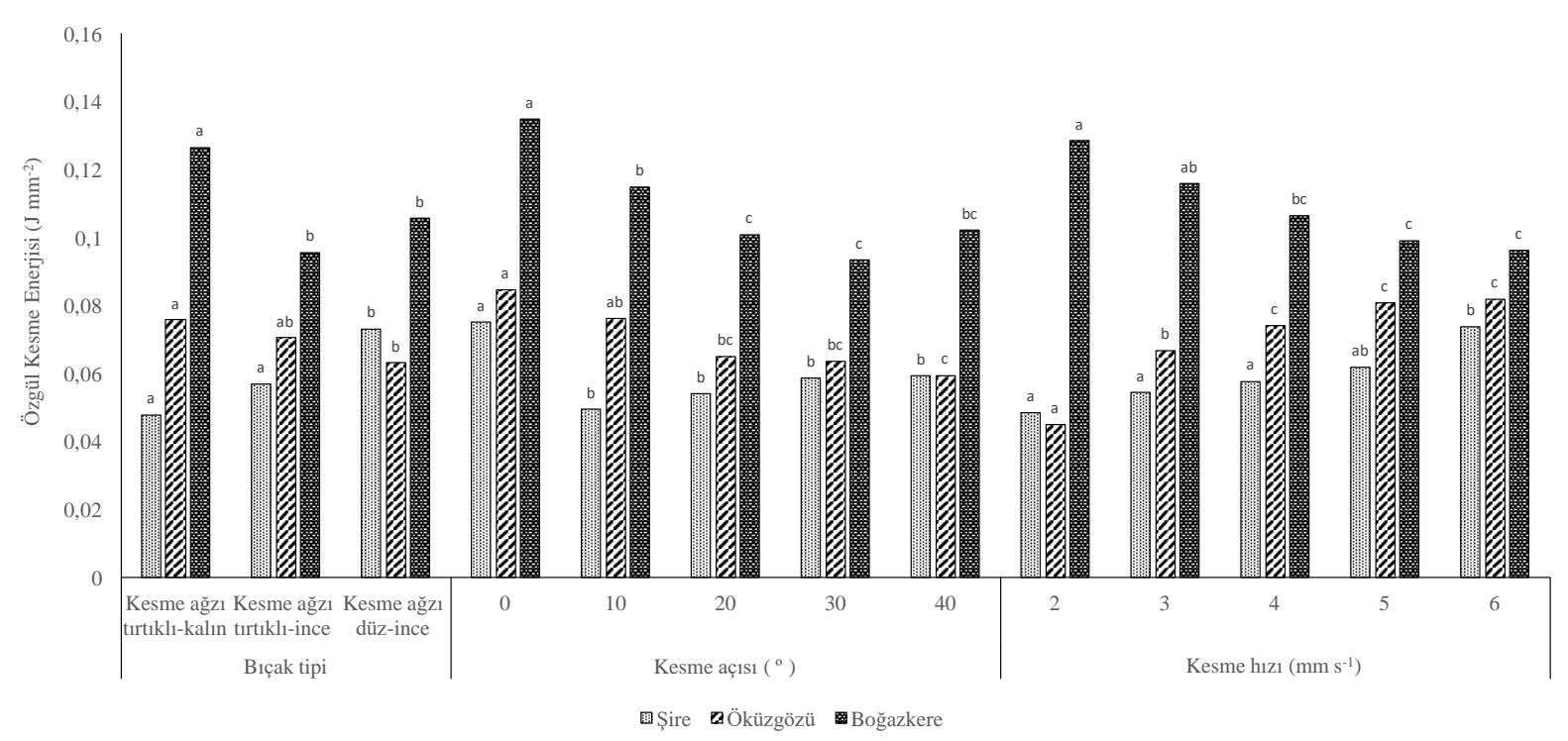

*Aynı harfle gösterilen ortalama değerler arasında \% 5 önem derecesine göre fark yoktur.

Şekil 6. Bıçak tipi, kesme açısı ve kesme hızına bağlı olarak özgül kesme enerjisinin değişimi.

Şekil 6'dan görüleceği bıçak tipleri arasındaki fark tüm çeşitlerde önemli bulunmuştur. Özgül enerji gereksinimi çeşit ve bıçak tipine göre farklılıklar göstermiştir. Kesme açısı yatay yönde arttıkça özgül kesme enerjisi değerlerinde kısmen azalma meydana gelmiştir. Ancak aralarındaki fark istatistiksel olarak önemsiz olmuştur. Özgül kesme enerjisi bakımından tüm çeşit ve bıçak tiplerinde benzer sonuçlar elde edilmiştir. Kesme enerjisi üç çeşit için de $20^{\circ}, 30^{\circ}$ ve $40^{\circ}$ bıçak kesme açıları arasındaki fark önemsiz bulunmuştur. Buna karşın en yüksek kesme enejisi değerleri en düşük kesme hızı olan $2 \mathrm{~mm} \mathrm{~s}^{-1}$ lik hızda elde edilmiştir. Bu hız değerinden sonra kesme hızları arttıkça Şire ve Öküzgözü çeşitlerinde artış olurken, Boğazkere çeşidinde azalma olmuştur. Bu durum kesme enerjisinde olduğu gibi muhtemelen çeşit özelliğinden kaynaklanmıştır.

\section{Sonuçlar}

Kesme testi sonuçlarına göre her üç çeşit için kesme özellikleri bıçak tipi, kesme açısı ve yükleme durumuna göre değişikliklikler göstermiştir. Kesme kuvveti ve enerji gereksinimi çeşitten çeşide farklı özellik göstermiştir. $\mathrm{Bu}$ durum, çeşidin kesmeye etkili bir faktör olduğunu göstermektedir. Genel olarak, kesme ağzı tırtıklı olan bıçak tiplerinde kesme kuvveti ve enerji değerleri kesme ağzı düz-ince olan bıçak tipine göre daha yüksek olmuştur. Kesme açısı artıkça kesme kuvveti ve kesme enejisi azalmıştır. En yüksek kesme kuvveti ve enerji değerleri $0^{\circ}$ açıda yapılan kesme işlemlerinde gerçekleşmiştir. Kesme hızlarının artışı kesme kuvveti, kesme gerilmesi, kesme enerjisi ve spesifik kesme enejisini hafif bir şekilde arttırmıştır. Tüm çeşitlerde en düşük değerler 2 $\mathrm{mm} \mathrm{s}^{-1}$ lik yükleme hızlarında elde edilmiştir.

\section{Kaynaklar}

Ammer Eissa, A.H., Gomaa, A.H., Baiomay, M.H., Ibrahim, A.A., 2008. Physical and mechanical characteristics for some agricultural residues. In Misr J Ag Eng, 25(1): 121-146.

Anastasiou, E., Balafoutis, A., Darra, N., Psiroukis, V., Biniari, A., Xanthopoulos, G., Fountas, S., 2018. Satellite and Proximal Sensing to Estimate the Yield and Quality of Table Grapes. Agriculture 2018, 8: 94.

Asabe Standarts 2006. S358.2: 1:1 Measurement Forages. 52nd edn. American Society of Agricultural Engineers, St Joseph MI.

Beyhan, M.A., 1996. Determination of shear strength of hazelnut sucker. J.Agric.Fac.OMU, 11(3): 167-181.

Chen, Y., Gratton, J.L., Liu, J., 2004. Power requirements of hemp cutting and conditioning. Biosystems Engineering, 87(4): 417-424. 
Ekinci, K., Yilmaz, D., Ertekin, C., 2010. Effects of moisture content and compression positions on mechanical properties of carob pod (Ceratonia siliqua L.). African Journal of Agricultural Research, 5(10): 10151021.

Emadi, B., Kosse, V., Yarlagadda, P., 2004. Relationship between mechanical properties of pumpkin and skin thickness. International Journal of Food Properties, 8(2): 277-287.

Esgici, R., Ozdemir, G., Pekitkan, F.G., Elicin, A.K., Ozturk, F. and Sessiz, A., 2017. Some enginnering properties of the Sire grape (Vitis Vinifera L.). Scientific Papers-Series B-Horticulture, 61: 195-203.

Ghahraei, O., Ahmad, D., Khalina, A., Suryanto, H., Othman, J. 2011. Cutting tests of kenaf stems. Transactions of the ASABE, 54(1):51-56.

Güzel, E., Zeren, Y., 1989. The theory of free cutting and rotary cutters. Agricultural Engineering, 1(4): 19531955.

Heidari, A., Chegini, G.R., 2011. Determining the shear strength and picking force of rose flower. Agricultural Engineering. Ejpau 14(2): 13.

Kocabiyik, H., Kayisoglu, B., 2004. Determination of shearing features of sunflower stalk. In J Agric Sci, vol. 10, 2004, no. 3: 263-267.

Lu, R., Siebenmorgen, T.J., 1995. Correlation of head rice yield to selected physical and mechanical properties of rice kernels. Transactions of the ASAE, 38(3): 889-894.

Mohsenin, N.N., 1986. Physical properties of plant and animals materials. 2nd edition. New York, NY: Gordon and Breach Science Publishers.

Morris, J.R., 2000. Past, Present, and future of vineyard mechanization. Proceeding ASEV 50 the Anniv. Ann. Mtg. Seatle, WA, 51: 155-164.

Nazari, G.M., Tabatabaeefar, A., Jafari, A., Sharifi, A., Rafiee, S., 2008. Bending and shearing characteristics of alfalfa stems. In Agricultural Engineering International: The CIGR Ejournal, Manuscript FP 08001 , Vol. X.

Nowakowski, T., 2016. Empirical model of unit energy requirements for cutting giant miscanthus stalks depending on grinding process parameters. Annals of Warsaw University of Life Sciences - SGGW, Agriculture (Agricultural and Forest Engineering) 67: 63-70.

Ozdemir, G., Sessiz, A., Esgici, R., Elicin, A.K., 2015. Cutting properties of wine grape cultivars. Scientific Papers. Series B, Horticulture. Vol. LIX: 151-158.

Pekitkan, F.G., Esgici, R., Elicin, A.K., Sessiz, A., 2018. The Change of Shear Force and Energy of Cotton Stalk Depend on Knife Type and Shear Angle. Scientific Papers. Series A. Agronomy, Vol. LXI, No. 1: 360366.

Persson, S., 1987. Mechanics of cutting plant material. ASAE Publications, St Joseph, MI, USA.

Sessiz, A., Güzel, E., Bayhan, Y., 2018. Bazı Yerli ve Yabancı Üzüm Çeşitlerinde Sürgünlerin Kesme Kuvveti ve Enerjisinin Belirlenmesi. Türk Tarım ve Doğa Bilimleri Dergisi (Turkish Journal of Agricultural and Natural Sciences). 5(4): 414-423.

Sessiz, A., Elicin, A.K., Esgici, R., Ozdemir, G., Nozdrovický, L., 2013. Cutting Properties of Olive Sucker. Acta Technologica Agriculturae. The Scientific Journal for Agricultural Engineering, The Journal of Slovak University of Agriculture in Nitra. 16(3): 80-84.

Sessiz, A., Esgici, R., Ozdemir, G., Elicin, A.K., Pekitkan, F.G., 2015. Cutting properties of different grape varieties. Agriculture \& Forestry, 6(1): 211-216.

Taghijarah, T., Ahmadi, H., Ghahderijani, M., Tavakoli, M., 2011. Shearing characteristics of sugar cane (Saccharum officinarum L.) stalks as a function of the rate of the applied force. AJCS 5(6): 630-634.

Yore, M.W., Jenkins, B.M., Summers, M.D., 2002. Cutting Properties of Rice Straw Paper Number: 026154.ASAE Annual International Meeting / CIGR XVth World Congress.

Zareiforoush, H., Mohtasebi, S.S., Tavakoli, H., Alizadeh, M.R., 2010. Effect of loading rate on mechanical properties of rice (Oryza sativa L.) straw. Australian Journal of Crop Science, 4(3): 190-195. 